\title{
IMRT delivers lower radiation doses to dental structures than 3DRT in head and neck cancer patients
}

Eduardo Rodrigues Fregnani ${ }^{1}$, Cláudia Joffily Parahyba ${ }^{1}$, Karina Morais-Faria², Felipe Paiva Fonseca², Pedro Augusto Mendes Ramos ${ }^{1}$, Fábio Yone de Moraes ${ }^{1,3}$, Karina Gondim Moutinho da Conceição Vasconcelos ${ }^{4}$, Gisela Menegussi ${ }^{4}$, Alan Roger Santos-Silva ${ }^{2 *}$ and Thais B. Brandão ${ }^{4}$

\begin{abstract}
Background: Radiotherapy (RT) is frequently used in the treatment of head and neck cancer, but different sideeffects are frequently reported, including a higher frequency of radiation-related caries, what may be consequence of direct radiation to dental tissue. The intensity-modulated radiotherapy (IMRT) was developed to improve tumor control and decrease patient's morbidity by delivering radiation beams only to tumor shapes and sparing normal tissue. However, teeth are usually not included in IMRT plannings and the real efficacy of IMRT in the dental context has not been addressed. Therefore, the aim of this study is to assess whether IMRT delivers lower radiation doses to dental structures than conformal 3D radiotherapy (3DRT).
\end{abstract}

Material and methods: Radiation dose delivery to dental structures of 80 patients treated for head and neck cancers (oral cavity, tongue, nasopharynx and oropharynx) with IMRT (40 patients) and 3DRT (40 patients) were assessed by individually contouring tooth crowns on patients' treatment plans. Clinicopathological data were retrieved from patients' medical files.

Results: The average dose of radiation to teeth delivered by IMRT was significantly lower than with 3DRT ( $p=0$. 007); however, only patients affected by nasopharynx and oral cavity cancers demonstrated significantly lower doses with IMRT ( $p=0.012$ and $p=0.011$, respectively). Molars received more radiation with both 3DRT and IMRT, but the latter delivered significantly lower radiation in this group of teeth $(p<0.001)$, whereas no significant difference was found for the other dental groups. Maxillary teeth received lower doses than mandibular teeth, but only IMRT delivered significantly lower doses $(p=0.011$ and $p=0.003)$. Ipsilateral teeth received higher doses than contralateral teeth with both techniques and IMRT delivered significantly lower radiation than 3DRT for contralateral dental structures $(p<0.001)$.

Conclusion: IMRT delivered lower radiation doses to teeth than 3DRT, but only for some groups of patients and teeth, suggesting that this decrease was more likely due to the protection of other high risk organs, and was not enough to remove teeth from the zone of high risk for radiogenic disturbance (>30Gy).

Keywords: Intensity-modulated radiotherapy, 3D radiotherapy, Head and neck cancer, Teeth, Dental structures

\footnotetext{
* Correspondence: alanroger@fop.unicamp.br

${ }^{2}$ Department of Oral Diagnosis (Pathology and Semiology), Piracicaba Dental

School, University of Campinas, Av. Limeira, 901 CEP 13414-903, Piracicaba,

São Paulo, Brazil

Full list of author information is available at the end of the article
} 


\section{Introduction}

Head and neck cancers (HNC) represent the sixth most common human malignancy in the world, with 442,760 new cases estimated for 2012 and a limited 5-years survival rate that achieves approximately $50 \%$ in most of the series [1, 2]. Radiotherapy (RT) is frequently used in the treatment of HNC patients; however, treatment-associated side effects like mucositis, trismus, dysphagia, skin fibrosis, dysgeusia, osteonecrosis and xerostomia are found in patients mainly because of the lack of specificity of conventional radiation therapy that in addition to the tumor mass, also targets adjacent normal tissues [3, 4]. Although some authors claimed that radiation would not lead to direct dental damage [5], most of the studies demonstrate that RT can cause dental hard tissue disturbance, especially in its organic component, what may explain the higher frequency of radiation-related caries [6-11].

In an attempt to improve disease control and to decrease patients' morbidity and toxicity, new RT planning techniques were developed. Intensity-modulated radiotherapy (IMRT) is a computerized optimization of the intensities of multiple radiation beams to strictly conform the treatment volume to tumor shapes, preserving adjacent normal structures, providing significantly better tumor target coverage and sparing sensitive normal tissue as compared with $3 \mathrm{D}$ radiotherapy (3DRT) in head and neck cancer $[3,12,13]$. Therefore, in this study we aimed to investigate if IMRT delivers lower radiation dose than 3DRT to dental structures.

\section{Material and methods}

This study was approved by the Research Ethics Committee of the Institute of Teaching and Research of the Sírio-Libanês Hospital (Protocol No. 430.556) and of the Cancer Institute of São Paulo (Protocol No.171.972). In a 5-year period from 2010 to 2015 we retrospectively analyzed dental radiation dosage data of $80 \mathrm{HNC}$ patients who underwent 3DRT (40 patients) and IMRT (40 patients) at the Cancer Institute of São Paulo and at the Sírio-Libanês Hospital, respectively.

Patients with clinicopathological information on age, gender, tumor location and clinical stage of the malignant disease and whose radiotherapy plans were available to be analyzed were included in this study. Patients were divided into four groups according to the primary tumor location (oral cavity, lateral border of tongue, oropharynx and nasopharynx). Patients on the 3DRT were treated in 6-MV linear accelerators on Synergy Platform (Elekta AB, Stockholm, Sweden) and received a mean radiation dose of 70Gy, whereas patients submitted to IMRT were treated on 6-18MV linear accelerator Novalis Tx Plataform on the Eclipse treatment planning system (Varian Medical Systems Inc., Palo Alto, CA, USA) and received a mean radiation dose of 66.7Gy.
Dosimetric analyses were performed for all patients by retrieving treatment planning and using calculation algorithms that incorporate tridimensional beam modeling on CMS XiO (Elekta CMS Software, St. Louis, MO) version 4.60 and Eclipse treatment planning system (Varian Medical Systems Inc., Palo Alto, CA, USA). Two previously trained dental oncologists, assisted by a medical physicist, reviewed each patient's treatment plans based on axial slices of computed tomography scans to calculate the cumulative dose for the crowns of each group of radiated teeth, which were divided into incisors (anterior), premolars and molars. These groups were further classified into right and left sides to be evaluated according to their laterality in relation to the irradiated tumor location (ipsilateral and contralateral teeth). The mean dose delivered to each group of teeth was determined by individually contouring tooth crowns on the treatment planning systems and the average and maximum point of doses for each group were calculated.

A descriptive analysis was performed for the clinicopathological features and for maximum and average radiation doses received by dental structures. $T$-test was used to compare 3DRT and IMRT data. One-way ANOVA test was used for identifying significant differences in the radiation doses received by teeth according to dental groups and primary tumors treated with 3DRT or IMRT. When significance in this test was achieved, it was followed by Tukey's Post-Hoc test to identify where significant differences were located. Minitab software version 17.3 and GraphPad Prism version 5.1 were used for statistical analyses and a $p$-value $<0.05$ using a $95 \%$ confidence interval was considered statistically significant.

\section{Results}

Demographic features obtained from the 80 patients analyzed are described in Table 1 . Of the 40 patients treated with 3DRT, 36 patients (90\%) also received concomitant chemotherapy, whereas 32 patients $(80 \%)$ of the 40 patients submitted to IMRT group also received chemotherapy. Radiotherapy was the primary treatment for 35 patients $(87.5 \%)$ and for 31 patients $(77.5 \%)$ of the 3DRT and IMRT groups, respectively, and adjuvant treatment for 5 patients $(12.5 \%)$ and for 9 patients $(22.5 \%)$ that received 3DRT and IMRT, respectively. In the 3DRT group 835 teeth were analyzed, whereas 1018 teeth were analyzed in the IMRT group.

Evaluating the overall dental doses delivered by both techniques, we observed that the mean of the average doses received by patients submitted to 3DRT was significantly higher than that delivered by $\operatorname{IMRT}(p=$ 0.007), although there was no significant difference in the mean maximum doses delivered ( $p=0.171)$ (Fig. 1). In addition, when primary tumor location was considered, there was no significant difference in dental doses 
Table 1 Clinicopathological features of the patients included in this study

\begin{tabular}{|c|c|c|}
\hline \multirow[t]{2}{*}{ Features } & \multicolumn{2}{|c|}{ No. patients (\%) } \\
\hline & 3DRT $(n=40)$ & IMRT $(n=40)$ \\
\hline \multicolumn{3}{|l|}{ Sex } \\
\hline Male & 35 (87.5 \%) & 29 (72.5\%) \\
\hline Female & $5(12.5 \%)$ & 11 (27.5\%) \\
\hline \multicolumn{3}{|l|}{ Age (years) } \\
\hline Mean & 54.9 & 48.0 \\
\hline Range & $25-81$ & $14-78$ \\
\hline \multicolumn{3}{|l|}{ Location } \\
\hline Tongue & 10 (25.0\%) & 10 (25.0\%) \\
\hline Oral Cavity & 10 (25.0\%) & 10 (25.0\%) \\
\hline Oropharynx & 10 (25.0\%) & 10 (25.0\%) \\
\hline Nasopharynx & 10 (25.0\%) & 10 (25.0\%) \\
\hline \multicolumn{3}{|l|}{ T stage } \\
\hline $\mathrm{T} 1$ & $6(15.0 \%)$ & 9 (22.5\%) \\
\hline $\mathrm{T} 2$ & $8(20.0 \%)$ & 9 (22.5\%) \\
\hline T3 & 9 (22.5\%) & 14 (35.0\%) \\
\hline T4 & 17 (42.5\%) & $8(20.0 \%)$ \\
\hline \multicolumn{3}{|l|}{ N stage } \\
\hline NO & 7 (17.5\%) & 7 (17.5 \%) \\
\hline N1 & 10 (25.0\%) & 9 (22.5\%) \\
\hline N2 & $21(52.5 \%)$ & $22(55.0 \%)$ \\
\hline N3 & $2(5.0 \%)$ & $2(5.0 \%)$ \\
\hline \multicolumn{3}{|l|}{ M stage } \\
\hline MO & 40 (100.0 \%) & 40 (100.0\%) \\
\hline M1 & 0 (0.0\%) & 0 (0.0\%) \\
\hline
\end{tabular}

received by patients affected by oral cavity, tongue, nasopharynx and oropharynx cancers treated with 3DRT (maximum dose $p=0.394$ and average dose $p=0.363$ ) (Fig. 2a). On the other hand, when treated with IMRT, patients affected by oral cavity cancer received significantly higher maximum doses than those affected by oropharynx cancer, whereas those affected by tongue cancer received significantly more radiation (average dose) than all other patients (variance analysis: maximum dose $p=0.007$ and average dose $p=0.002$ ) (Fig. 2b). Furthermore, we observed that patients affected by nasopharynx (maximum and average doses, $p=0.041$ and $p=0.012$, respectively) and oral cavity (average dose, $p=0.011$ ) cancers treated with 3DRT received significantly more dental radiation than those treated with IMRT, whereas patients affected by tongue cancer treated with IMRT received more radiation than those treated with 3DRT, although this difference was not significant (maximum and average doses, $p=0.094$ and $p=0.395$ ) (Fig. 2c).

Radiation doses received by patients treated with 3DRT and IMRT according to dental groups and primary tumors are summarized in Table 2. 3DRT and IMRT both delivered higher radiations doses (maximum and average doses) to molars than to anterior teeth (variance analysis: $p<0.001$ for 3DRT and IMRT) (Fig. 3a and b). When both techniques were compared, we found that molars of patients treated with IMRT received significantly less radiation than those of patients treated with 3DRT ( $p=0.001$ and $p<0.001$, for maximum and average doses, respectively), whereas anterior teeth received more radiation with IMRT, but without statistical significance $(p=0.066$ and $p=0.363$, for maximum and average dose, respectively) (Fig. 3c).

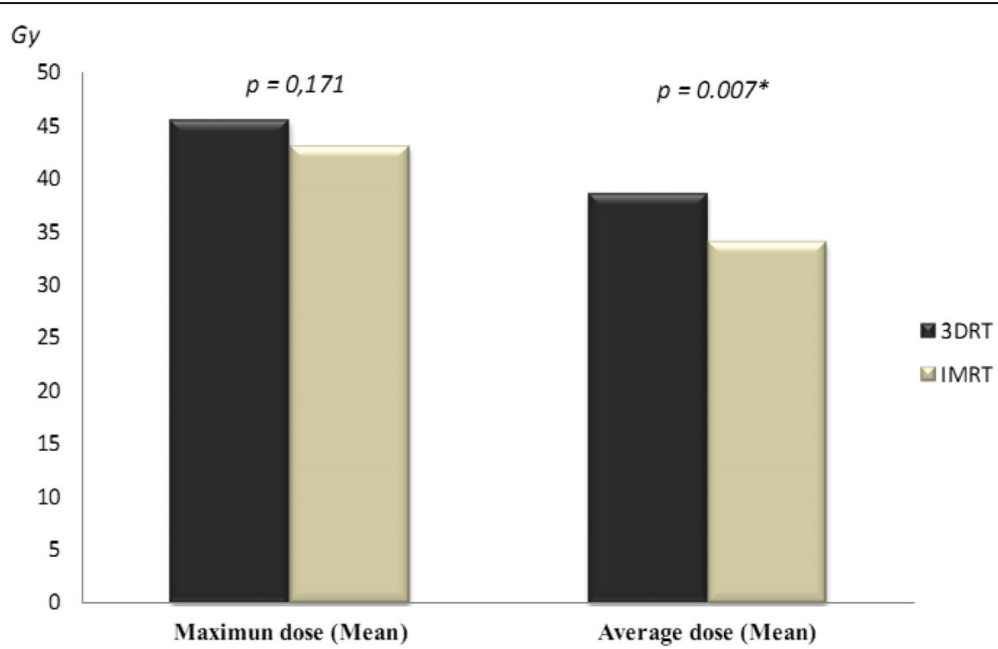

Fig. 1 Mean of the maximum and of the average dental doses delivered by 3DRT and IMRT to patients treated for head and neck cancers. Legend: * Statistically significant difference according to $t$-test. 3DRT mean of the maximum dose $45.4 \mathrm{~Gy}$ ( $\pm 24.8 \mathrm{~Gy})$ and mean of the average dose 38.5 Gy ( \pm 24.5 Gy). IMRT mean of the maximum dose 43.0 Gy ( \pm 17.8 Gy) and mean of the average dose 34.0 Gy ( \pm 15.6 Gy) 


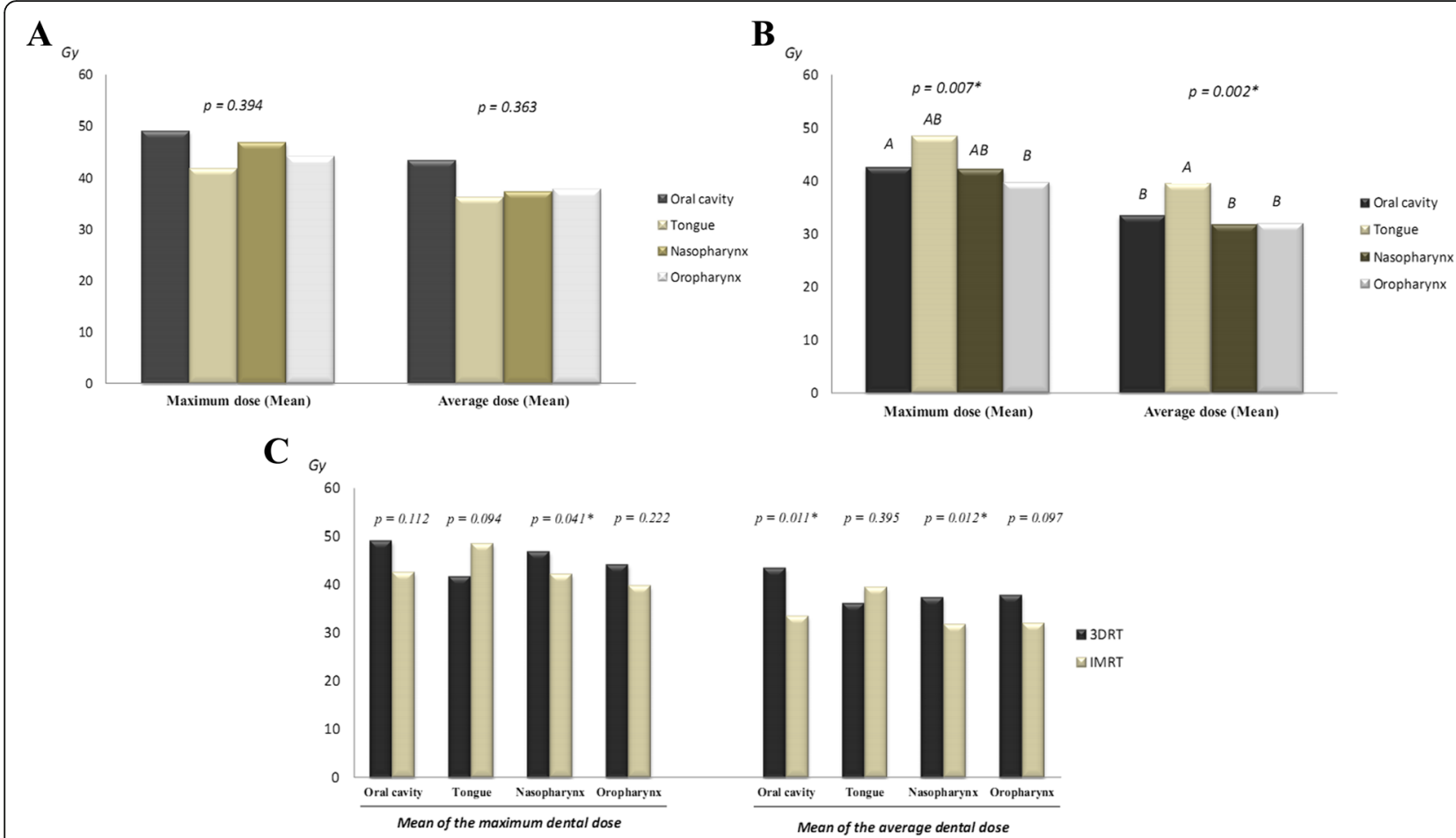

Fig. 2 Mean of the maximum and of the average dental doses delivered by 3DRT and IMRT according to the location of the primary tumor treated. a There was no significant difference in the radiation doses (maximum and average) delivered by 3DRT to all HNC treated. Legend: There was no statistically significant difference according to One-way ANOVA test. Mean of the maximum doses: Oral cavity $49.02 \mathrm{~Gy}( \pm 27.69 \mathrm{~Gy})$, tongue $41.64 \mathrm{~Gy}( \pm 25.34 \mathrm{~Gy})$, nasopharynx $46.83 \mathrm{~Gy}( \pm 16.51 \mathrm{~Gy})$ and oropharynx $44.14 \mathrm{~Gy}( \pm 28.06 \mathrm{~Gy})$. Mean of the average doses: Oral cavity $43.39 \mathrm{~Gy}$ ( $\pm 26.47 \mathrm{~Gy}$ ), tongue $36.08 \mathrm{~Gy}$ ( $\pm 25.51 \mathrm{~Gy}$ ), nasopharynx $37.27 \mathrm{~Gy}$ ( $\pm 17.14 \mathrm{~Gy}$ ) and oropharynx $37.76 \mathrm{~Gy}$ ( $\pm 27.69 \mathrm{~Gy})$. b On the other hand, IMRT delivered significantly higher dental doses to patients treated for oral cavity if compared to oropharynx (maximum dose) cancer and to tongue if compared to all other cancers (average dose). Legend: * Statistically significant difference according to One-way ANOVA test. Different letters represent statistically different groups according to Tukey's Post Hoc test. Mean of the maximum doses: Oral cavity 42.47 Gy ( \pm 18.07 Gy), tongue $48.36 \mathrm{~Gy}( \pm 19.11 \mathrm{~Gy})$, nasopharynx $42.06 \mathrm{~Gy}( \pm 12.94 \mathrm{~Gy})$ and oropharynx $39.67 \mathrm{~Gy}$ ( $\pm 19.60 \mathrm{~Gy})$. Mean of the average doses: Oral cavity 33.40 Gy ( \pm 16.37 Gy), tongue 39.41 Gy ( \pm 17.89 Gy), nasopharynx 31.68 Gy ( \pm 9.23 Gy) and oropharynx 31.95 Gy ( \pm 16.81 Gy). c Comparing both techniques we observed that 3DRT delivered significantly higher dental doses to patients treated for nasopharynx (maximum and average doses) and oral cavity (average dose) cancers than IMRT. Legend: * Statistically significant difference according to $t$-test

Radiation doses delivered by 3DRT and IMRT to lower (mandibular) and upper (maxillary) teeth were also investigated. There was no significant difference in the doses delivered between both techniques to maxillary teeth (mean of the average $p=0.101$ and mean of the maximum $p=0.521$ ), but the mean average of radiation delivered by IMRT to mandibular teeth was significantly lower than 3DRT (mean of the average $p=0.043$ and mean of the maximum $p=0.29$ ) (Table 3). Maxillary teeth received lower doses of radiation than mandibular teeth, but significance was achieved only with IMRT technique (mean of the maximum $p=0.011$ and mean of the average $p=0.003$ ). By investigating maxillary and mandibular dosages according to primary tumors, we found statistically significant difference in the mean average and mean maximum doses delivered by 3DRT to tongue cancer $(p=0.0007$ and $p=0.0003$, respectively) and in the mean average delivered by IMRT to oral cavity cancers $(p=0.025)$ (Table 4$)$.
Ipsilateral dental groups received higher doses than contralateral teeth submitted to both 3DRT and IMRT, although statistical significance was achieved only for patients treated with latter $(p<0.001$ for both maximum and average doses) (Fig. 4a). Comparing both techniques, IMRT delivered less radiation to both ipsilateral and contralateral teeth than 3DRT; however, statistical significance was obtained only for contralateral teeth $(p=0.004$ and $p<0.001$, for maximum and average doses, respectively) (Fig. $4 \mathrm{~b}$ ).

\section{Discussion}

$\mathrm{HNC}$ is an aggressive human disease with unsatisfactory 5 -years survival rates. Improvements in the radiotherapy delivery techniques to increase tumor control and decrease patients' toxicity and morbidity led to the development of IMRT that constrains radiation beams to tumor volume and limits the involvement of adjacent normal tissues, tightly modulating the radiation intensity 
Table 2 Mean of the maximum and mean of the average dosages (Gy) received by dental groups of patients submitted to IMRT and 3DRT protocols



for each area of the target [12]. Consequently, patients submitted to IMRT have lower risks of osteoradionecrosis of the jaws, less xerostomia, less pain and lower incidence of mucositis when compared to those receiving 3DRT, with an improved global quality of life [14, 15], what affirms the superiority of IMRT to obtain less RT related toxicity [16].

Radiation-related caries are a common complication of anti-neoplastic therapy that mainly affect the vestibular, cervical and oclusal/incisional dental surfaces and cause extensive enamel loss that gives rise to an extensive brownish discoloration of the teeth. Our group has previously demonstrated that pulpal components of irradiated teeth are not directly affected by radiation [5, 17], supporting the hypothesis that radiation-related caries would primarily represent a consequence of modifications in saliva production by irradiated salivary glands that would alter saliva composition, reduce oral clearance and cause significant changes of the oral microflora, increasing the concentration of acidogenic and cariogenic microorganisms [18]. However, different studies have documented direct alterations in the enamel, dentin and enamel-dentin junction (EDJ), what would be responsible for or facilitate the development of radiationrelated caries [6, 8]. Therefore, according to these studies, protecting dental hard tissues from direct radiation would represent an important objective during head and neck radiotherapy.

Some studies attempted to demonstrate the radiation dosage received by dental structures and tooth-bearing regions of patients that received 3DRT and IMRT for HNC treatment $[4,19,20]$; however, there seems to be no previous analysis comparing the dental radiation doses delivered by both approaches. In this context, we demonstrated in this survey that patients treated with IMRT received significantly lower doses of dental radiation than those treated with 3DRT. However, when we considered the location of primary tumors only patients affected by nasopharynx and oral cavity cancers demonstrated statistically significant lower doses when treated with IMRT. In our opinion, this finding more likely represents an indirect dental benefit, because teeth are not included in the IMRT constrained areas during radiation planning, what allow us to further speculate that the lower dental radiation doses obtained with IMRT only for these patients would be an indirect advantage of the protection of other high risk organs like the salivary glands. Moreover, the contradictory result found for tongue cancer that revealed lower dental doses with 3DRT also corroborate our hypothesis of indirect benefit of IMRT to dental structures, since we believe that patients affected by any HNC should have demonstrated a homogeneous lower dental dose with IMRT if teeth were spared in the radiation planning.

In our study, with no dental constrain during IMRT planning, we observed that only 10 out of 23 dental groups analyzed received less than $30 \mathrm{~Gy}$ as an average radiation dose, and only one dental group (upper anterior teeth of oropharynx cancer patients) received less 


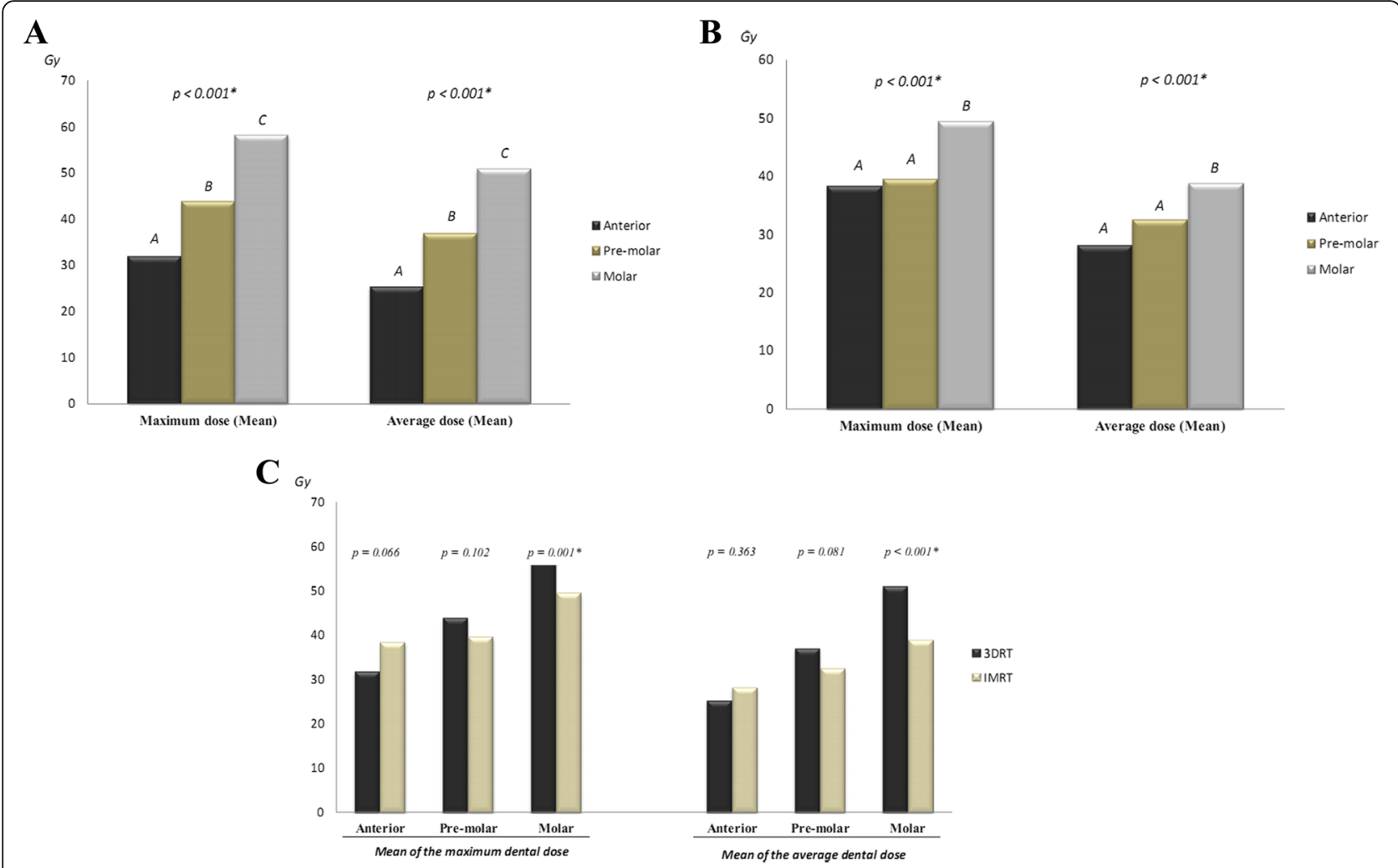

Fig. 3 Mean of the maximum and of the average dental doses delivered by 3DRT and IMRT according to the dental groups investigated. a In the group of patients treated with 3DRT, molars received significantly higher doses (maximum and average doses) than pre-molar and anterior teeth, whereas pre-molars received significantly more radiation (maximum and average doses) than anterior teeth. Legends: * Statistically significant difference according to One-way ANOVA variance test. Different letters represent statistically different groups according to Tukey's Post Hoc test. Mean of the maximum doses: Anteriors 31.74 Gy ( $\pm 23.68 \mathrm{~Gy}$ ), pre-molars $43.67 \mathrm{~Gy}( \pm 23.49 \mathrm{~Gy})$ and molars $58.02 \mathrm{~Gy}( \pm 20.99 \mathrm{~Gy})$. Mean of the average doses: Anteriors $25.20 \mathrm{~Gy}( \pm 23.03 \mathrm{~Gy})$, pre-molars $36.82 \mathrm{~Gy}( \pm 23.24 \mathrm{~Gy})$ and molars $50.75 \mathrm{~Gy}( \pm 21.30 \mathrm{~Gy})$. b In the group of patients treated with IMRT, molars also received significantly higher doses (maximum and average doses) than pre-molar and anterior teeth, but there was no significant difference between the last two groups. Legends: * Statistically significant difference according to One-way ANOVA variance test. Different letters represent statistically different groups according to Tukey's Post Hoc test. Mean of the maximum doses: Anteriors 38.19 Gy ( $\pm 17.30 \mathrm{~Gy})$, pre-molars $39.39 \mathrm{~Gy}$ ( $\pm 17.41 \mathrm{~Gy})$ and molars $49.34 \mathrm{~Gy}$ ( $\pm 16.63 \mathrm{~Gy})$. Mean of the average doses: Anteriors $28.14 \mathrm{~Gy}$ ( $\pm 14.35 \mathrm{~Gy})$, premolars $32.43 \mathrm{~Gy}( \pm 15.18 \mathrm{~Gy})$ and molars $38.74 \mathrm{~Gy}( \pm 15.36 \mathrm{~Gy})$. c When we compared dental groups according to the technique used, we observed that in patients treated with 3DRT molars received significantly more radiation (maximum and average doses) than those treated with IMRT. Legends: * Statistically significant difference according to $t$-test

than 30Gy as the mean maximum dose; moreover, the total amount of dental radiation delivered by IMRT was of 34Gy and 43Gy (mean of the average and mean of the maximum doses). These results show that even using IMRT, dental structures were exposed to radiation doses above the cut off value of 30Gy proposed by Walker et al. [6] that would expose patients to a 2-3 times higher risk for direct dental hard tissue disturbance.

This observation demonstrates that by not including teeth in the constrained plans of IMRT, the significant decrease in the radiation doses obtained when compared to 3DRT were not enough to remove teeth from the

Table 3 Radiation doses delivered to lower (maxillary) and upper (mandibular) teeth using 3DRT and IMRT

\begin{tabular}{|c|c|c|c|c|}
\hline & \multicolumn{2}{|l|}{ 3DRT } & \multicolumn{2}{|l|}{ IMRT } \\
\hline & Mean average & Mean maximum & Mean average & Mean maximum \\
\hline Maxillary teeth & $35.66( \pm 24.75)^{\mathrm{aA}}$ & $42.74( \pm 24.87)^{\mathrm{aA}}$ & $31.95( \pm 15.51)^{\mathrm{aA}}$ & $41.21( \pm 18.01)^{\mathrm{aA}}$ \\
\hline Mandibular teeth & $41.34( \pm 24.07)^{\mathrm{aA}}$ & $48.42( \pm 24.36)^{\mathrm{aA}}$ & $36.79( \pm 15.65)^{\mathrm{bB}}$ & $45.94( \pm 17.43)^{\mathrm{bA}}$ \\
\hline
\end{tabular}

Different lower case letters in columns mean statistically significant difference $(p<0.05)(t$-test). In columns, compare 3DRT groups themselves and IMRT groups themselves

Different upper case letters in rows mean statistically significant difference $(p<0.05)$ (One way ANOVA test). In rows, compare mean of the averages themselves and mean of the maximums themselves 
Table 4 Radiation doses delivered to lower (maxillary) and upper (mandibular) teeth using 3DRT and IMRT according to the primary site of the tumor

\begin{tabular}{|c|c|c|c|c|c|c|c|c|c|}
\hline & \multicolumn{2}{|l|}{ Oral cavity } & \multicolumn{2}{|l|}{ Tongue } & \multicolumn{2}{|l|}{ Oropharynx } & \multicolumn{2}{|l|}{ Nasopharynx } \\
\hline & & $\begin{array}{l}\text { Mean } \\
\text { average }\end{array}$ & $\begin{array}{l}\text { Mean } \\
\text { maximum }\end{array}$ & $\begin{array}{l}\text { Mean } \\
\text { average }\end{array}$ & $\begin{array}{l}\text { Mean } \\
\text { maximum }\end{array}$ & $\begin{array}{l}\text { Mean } \\
\text { average }\end{array}$ & $\begin{array}{l}\text { Mean } \\
\text { maximum }\end{array}$ & $\begin{array}{l}\text { Mean } \\
\text { average }\end{array}$ & $\begin{array}{l}\text { Mean } \\
\text { maximum }\end{array}$ \\
\hline \multirow[t]{2}{*}{ 3DRT } & Maxilla & $43.38( \pm 27.27)^{\mathrm{aA}}$ & $48,17( \pm 27.24)^{\mathrm{aA}}$ & $25,31( \pm 24.36)^{\mathrm{aB}}$ & $30,26( \pm 24.81)^{\mathrm{aB}}$ & $37,75( \pm 27.36)^{\mathrm{aAB}}$ & $44,85( \pm 27.28)^{\mathrm{aA}}$ & $34,83( \pm 17.21)^{\mathrm{aAB}}$ & $45,28( \pm 17.02)^{a A B}$ \\
\hline & Mandible & $43.41( \pm 26.01)^{\mathrm{aA}}$ & $50,86( \pm 28.29)^{\mathrm{aA}}$ & $47,64( \pm 21.66)^{\mathrm{bA}}$ & $53,51( \pm 19.59)^{\mathrm{bA}}$ & $36,99( \pm 28.47)^{\mathrm{aA}}$ & $43,47( \pm 29.08)^{\mathrm{aA}}$ & $40,13( \pm 16.85)^{\mathrm{aA}}$ & $48,66( \pm 15.95)^{\mathrm{aA}}$ \\
\hline \multirow[t]{2}{*}{ IMRT } & Maxilla & $29.58( \pm 15.02)^{\mathrm{aA}}$ & $39.76( \pm 17.58)^{\mathrm{aA}}$ & $35.63( \pm 19.88)^{\mathrm{aA}}$ & $44.07( \pm 21.33)^{\mathrm{aA}}$ & $29.93( \pm 16.06)^{\mathrm{aA}}$ & $38.04( \pm 19.77)^{\mathrm{aA}}$ & $31.75( \pm 8.99)^{\mathrm{aA}}$ & $41.38( \pm 12.24)^{\mathrm{aA}}$ \\
\hline & Mandible & $37.31( \pm 16.93)^{\mathrm{bAB}}$ & $45.23( \pm 18.35)^{\mathrm{aAB}}$ & $42.93( \pm 15.20)^{\mathrm{a} A B}$ & $52.37( \pm 15.99)^{\mathrm{aAB}}$ & $33.92( \pm 17.44)^{\mathrm{aA}}$ & $41.28( \pm 19.51)^{\mathrm{aA}}$ & $31.62( \pm 9.56)^{\mathrm{aA}}$ & $42.74( \pm 13.69)^{\mathrm{aA}}$ \\
\hline
\end{tabular}

Different lower case letters in columns mean statistically significant difference $(p<0.05)(t$-test). In columns, compare 3DRT groups themselves and IMRT groups themselves

Different upper case letters in rows mean statistically significant difference $(p<0.05)$ (One way ANOVA test + Tukey's post-hoc test). In rows, compare mean of

the averages themselves and mean of the maximums themselves

zone of high risk for radiogenic disruption. This rationale explains the findings described by Duarte et al. [21] who failed to obtain a significant difference in the number of caries developed by patients treated by 3DRT and IMRT, by Kataoka et al. [17] and Kataoka et al. [22] who also failed to demonstrate any significant difference on dental pulp sensitivity of patients treated with IMRT and 3DRT and by Beesley et al. [23] that found no difference in tooth loss between both modalities. In addition, Gomez et al. [24] also observed that $17 \%$ of their sample (168 patients) experienced a dental event (caries or tooth loss) during follow-up after IMRT therapy.

All these results suggest that teeth must be included in the IMRT planning to decrease dental radiation exposure and to obtain all benefits of this approach in the dental context. This assumption is also supported by Verdonck et al. [25] who reported lower radiation doses in the anterior mandible of patients affected by oropharynx cancer when IMRT planning was appropriately performed, allowing the use of anterior dental implants in these patients.

In this study we also found significantly higher doses of radiation in posterior teeth using both 3DRT and IMRT. This finding is in accordance to Bak et al. [26] that using IMRT obtained higher doses of radiation in molars of patients affected by cancers from the base of the tongue, tonsil and hypopharynx. Similarly, Hansen et al. [27] and Parahyba et al. [20] also obtained higher radiation values for molars, reporting that tumor size is very important to predict the amount of radiation delivered to tooth-bearing regions, since large tumors revealed high doses in the entire mandible, for this reason we attempted to gather tumors with as much similar TNM stage as possible.

On the other hand, we observed that only molars demonstrated significantly lower dental doses with
A

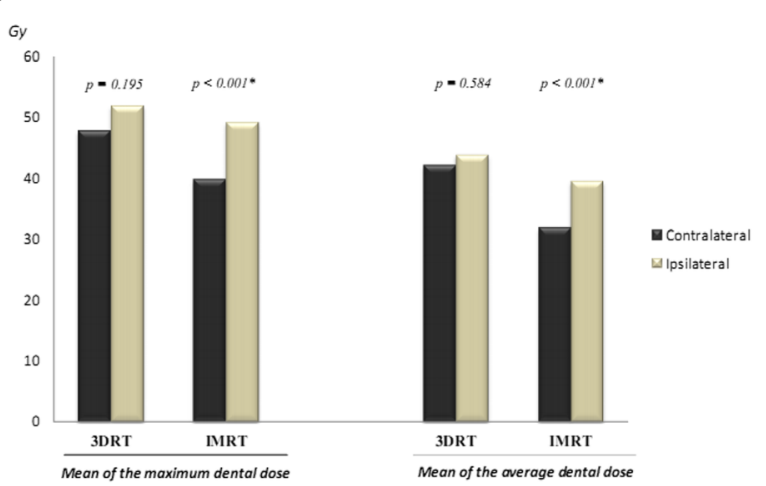

B

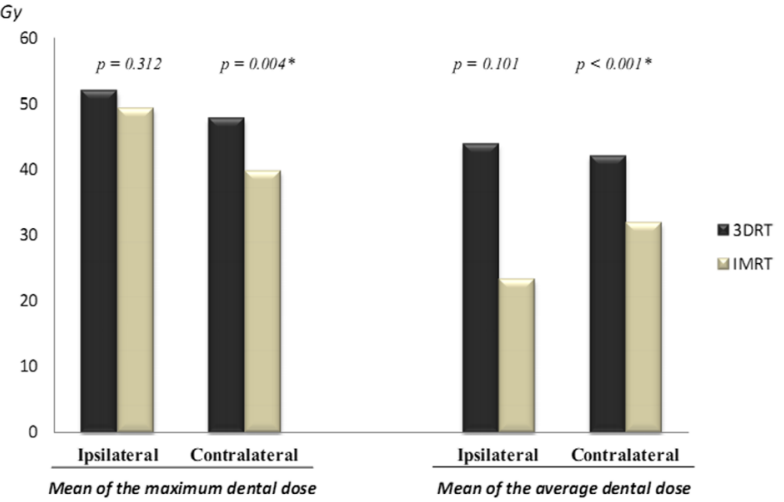

Fig. 4 Mean of the maximum and of the average dental doses delivered by 3DRT and IMRT according to the dental laterality in regard to primary tumors. a Teeth located ipsilateral to primary tumor received higher doses of radiation than their contralateral counterparts; however, this difference was significantly different only for those patients treated with IMRT. Legends: * Statistically significant difference according to $t$-test. Mean of the maximum doses: Contralateral teeth (3DRT) $47.70 \mathrm{~Gy}$ ( $\pm 23.30 \mathrm{~Gy}$ ) and ipsilateral teeth (3DRT) 51.90 Gy ( $\pm 23.60 \mathrm{~Gy}$ ); contralateral teeth (IMRT) $39.70 \mathrm{~Gy}( \pm 17.30 \mathrm{~Gy})$ and ipsilateral teeth (IMRT) $49.20 \mathrm{~Gy}( \pm 17.00 \mathrm{~Gy}$ ). Mean of the average doses: Contralateral teeth (3DRT) 42.00 Gy ( $\pm 23.60 \mathrm{~Gy})$ and ipsilateral teeth (3DRT) $43.80 \mathrm{~Gy}$ ( $\pm 23.30 \mathrm{~Gy})$; contralateral teeth (IMRT) $31.80 \mathrm{~Gy}$ ( $\pm 14.70 \mathrm{~Gy})$ and ipsilateral teeth (IMRT) $39.50 \mathrm{~Gy}$ ( $\pm 15.50 \mathrm{~Gy}$ ). $\mathbf{b}$ When we compared both techniques we observed that contralateral teeth of patients treated with 3DRT received statistically more radiation than those treated with IMRT. Legends: * Statistically significant difference according to t-test 
IMRT than with 3DRT, whereas anterior teeth presented higher, although non-significant, radiation doses with IMRT. Once again, this variability in the doses received by different dental groups also supports our hypothesis of an indirect benefit obtained with IMRT.

Mandibular teeth seems to be more irradiated than maxillary teeth irrespective of primary tumor site when using 3DRT [4], what could also be demonstrated in our study. However, a recent report demonstrated lower mandibular doses in patients affected by nasopharynx cancer treated by IMRT [20], suggesting that using this technique primary tumor location would determine the most irradiated jaw. This finding was also observed in our sample, since only patients affected by nasopharynx cancer exhibited a slightly lower mean average radiation in mandibular teeth if compared to maxillary ones. IMRT also provided less radiation doses to teeth located either ipsilateral or contralateral in relation to primary tumor, but with a significant difference to 3DRT only for those teeth positioned contralateral to the lesion. The lower radiation doses observed in contralateral teeth had also been previously described $[4,20]$.

\section{Conclusion}

In conclusion, we showed in this study that even when teeth are not constrained for radiation exposal during IMRT treatment for $\mathrm{HNC}$, it provides significantly lower radiation doses to dental hard tissues if compared to 3DRT, but only for some groups of patients and teeth, what may represent an indirect advantage as a consequence of the protection of other high risk organs. However, these lower radiation doses were not enough to remove teeth from the band of high risk for radiogenic dental disruptions (> 30Gy), suggesting that teeth must be included in the IMRT sparring plans so that we can benefit from the advantages of this technique for dental health maintenance. Nevertheless, studies comparing the radiation doses delivered to teeth with and without including dental structures in IMRT constrained plans remain to be performed to confirm this hypothesis.

\section{Acknowledgements}

Not applicable.

\section{Funding}

None.

Availability of data and materials

Not applicable.

\section{Authors' contributions}

ERF - Study design, data analysis and statistical analysis. CJP - Data analysis and assessment of dental radiation doses. KMF - Data analysis and assessment of dental radiation doses. FPF - Data analysis, statistical analysis and manuscript writing. PAMR - Data analysis and manuscript writing. FYM Data analysis and manuscript writing. KGMCV - Data analysis and manuscript writing. GM - Data analysis and manuscript writing. ARSS - Study design and data analysis. TBB - Study design and data analysis. All authors read and approved the final manuscript.

\section{Competing interests}

The authors declare that they have no competing interests.

Consent for publication

Not applicable.

\section{Ethics approval and consent to participate}

This study was approved by the Research Ethics Committee of the Institute of Teaching and Research of the Sírio-Libanês Hospital (Protocol No. 430.556) and of the Cancer Institute of São Paulo (Protocol No.171.972). Patients provided informed consent prior to participation in this study.

\section{Author details}

${ }^{1}$ Departments of Radiation Oncology and Oral Medicine, Sírio-Libanês Hospital, São Paulo, Brazil. 'Department of Oral Diagnosis (Pathology and Semiology), Piracicaba Dental School, University of Campinas, Av. Limeira, 901 CEP 13414-903, Piracicaba, São Paulo, Brazil. ${ }^{3}$ Radiation Medicine Program, Princess Margaret Hospital, University of Toronto, Toronto, ON, Canada. ${ }^{4}$ Dental Oncology Service, Instituto do Câncer do Estado de São Paulo (ICESP), Faculdade de Medicinada Universidade de São Paulo, São Paulo, Brazil.

Received: 30 May 2016 Accepted: 2 September 2016

Published online: 07 September 2016

References

1. Pontes FSC, Carneiro JT, Fonseca FP, et al. Squamous cell carcinoma of the tongue and floor of the mouth: Analysis of survival rate and independent prognostic factors in the Amazon region. J Craniofac Surg. 2011;22:925-30.

2. Curado MP, Johnson NW, Kerr AR, et al. Oral and oropharynx cancer in South America: Incidence, mortality trends and gaps in public databases as presented to the Global Oral Cancer Forum. Transl Res Oral Oncol. 2016;1:1-7.

3. Ballivy O, Santamaría RG, Borbalas AL, et al. Clinical application of intensitymodulated radiotherapy for head and neck cancer. Clin Transl Oncol. 2008; 10:407-14.

4. Morais-Faria K, Menegussi G, Vasconcelos KGMC, et al. Dosimetric distribution to the teeth of patients with head and neck cancer who underwent radiotherapy. Oral Surg Oral Med Oral Pathol Oral Radiol. 2015;120:416-9.

5. Faria KM, Brandão TB, Ribeiro ACP, et al. Micromorphology of the dental pulp is highly preserved in cancer patients who underwent head and neck radiotherapy. J Endod. 2014;40:1553-9.

6. Walker MP, Wichman B, Cheng AL, et al. Impact of radiotherapy dose on dentition breakdown in head and neck cancer patients. Pract Radiat Oncol. 2011;1:142-8.

7. Gonçalves LMN, Palma-Dibb RG, Paula-Silva FWG, et al. Radiation therapy alters microhardness and microstructure of enamel and dentin of permanent human teeth. J Dent. 2014;42:986-92.

8. Lieshout HFJ, Bots CP. The effect of radiotherapy on dental hard tissue - a systematic review. Clin Oral Invest. 2014;18:17-24.

9. McGuire JD, Mousa AA, Zhang BJ, et al. Extracts of irradiated mature human tooth crowns contain MMP-20 protein and activity. J Dent. 2014;42:626-35.

10. McGuire JD, Gorski JP, Dusevich V, et al. IV collagen is a novel DEJ biomarker that is reduced by radiotherapy. J Dent Res. 2014;93:1028-34.

11. Reed $R, X u C$, Liu Y, et al. Radiotherapy effect on nano-mechanical properties and chemical composition of enamel and dentine. Arch Oral Biol. 2015;60:690-7.

12. Lee $\mathrm{N}$, Puri DR, Blanco Al, et al. Intensity-modulated radiation therapy in head and neck cancers: an update. Head Neck. 2007:29:387-400.

13. Studer G, Zwahlen RA, Graetz KW, et al. IMRT in oral cavity cancer. Radiation Oncol. 2007;2:16-23.

14. Tribius S, Bergelt C. Intensity-modulated radiotherapy versus conventional and $3 \mathrm{D}$ conformal radiotherapy in patients with head and neck cancer: Is there a worthwhile quality of life gain? Cancer Treat Rev. 2011;37:511-9.

15. Chen AM, Farwell G, Luu Q, et al. Intensity-modulated radiotherapy is associated with improved global quality of life among long-term survivors of head-and-neck cancer. Int J Radiation Oncol Biol Phys. 2012;84:170-5. 
16. Mendez LC, Moraes FY, Poon I, et al. The management of head and neck tumors with high technology radiation therapy. Expert Rev Anticancer Ther. 2016;16:99-110

17. Kataoka SH, Setzer FC, Fregnani ER, et al. Effects of 3-dimensional conformal or intensity-modulated radiotherapy on dental pulp sensitivity during and after the treatment of oral or oropharyngeal malignancies. J Endod. 2012:38:148-52

18. Gupta N, Pal M, Rawat S, et al. Radiation-induced caries, prevention and treatment - A systematic review. Natl J Maxillofac Surg. 2015;6:160-6.

19. Monroe AT, Flesher-Bratt D, Morris CG, Peddada AV. Prospectively-collected, tooth-specific dosimetrycorrelated with adverse dental outcomes. Oral Surg Oral Med Oral Pathol Oral Radiol. 2016;122(2):158-63. doi:10.1016/j.00oo. 2016.03.005

20. Parahyba CJ, Moraes FY, Ramos PAMM, et al. Radiation dose distribution in the teeth, maxilla, and mandible of patients with oropharyngeal and nasopharyngeal tumors who were treated with intensity-modulated radiotherapy. Head Neck. 2016 (in press).

21. Duarte VM, Liu YF, Rafizadeh S, et al. Comparison of dental health of patients with head and neck cancer receiving IMRT vs conventional radiation. Otolaryngol Head Neck Surg. 2014;150:81-6.

22. Kataoka SH, Setzer FC, Gondim-Junior E, et al. Late effects of head and neck radiotherapy on pulp vitality assessed by pulse oximetry. J Endod. 2016. (in press).

23. Beesley R, Rieger J, Compton S, et al. Comparison of tooth loss between intensity-modulated and conventional radiotherapy in head and neck cancer patients. J Otolaryngol Head Neck Surg. 2012:41:389-95.

24. Gomez DR, Estilo CL, Wolden SL, et al. Correlation of osteoradionecrosis and dental events with dosimetric parameters in intensity-modulated radiation therapy for head-and-neck cancer. Int J Radiation Oncology Biol Phys. 2011;81:e207-13.

25. Verdonck HWD, Jong JMA, Granzier MEPG, et al. Intensity-modulated radiation therapy for oropharyngeal cancer: Radiation dosage constraint at the anterior mandible. Oral Oncol. 2009:45:511-4.

26. Bak SY, Qi XS, Kelly JA, et al. Dosimetric distribution to tooth-bearing areas in intensity-modulated radiation therapy for head and neck cancer: a pilot study. Oral Surg Oral Med Oral Pathol Oral Radiol. 2016;121:43-8.

27. Hansen HJ, Maritim B, Bohle III GC, et al. Dosimetric distribution to the tooth-bearing regions of the mandible following intensity-modulated radiation therapy for base of tonque cancer. Oral Surg Oral Med Oral Pathol Oral Radiol. 2012;114:e50-4.

\section{Submit your next manuscript to BioMed Central and we will help you at every step:}

- We accept pre-submission inquiries

- Our selector tool helps you to find the most relevant journal

- We provide round the clock customer support

- Convenient online submission

- Thorough peer review

- Inclusion in PubMed and all major indexing services

- Maximum visibility for your research

Submit your manuscript at www biomedcentral.com/submit

) Biomed Central 